Tatsuro Kondoh • Akira Tsuru • Tadashi Matsumoto

Tetsuo Matsuzaka $\cdot$ Yoshiro Tsuji

\title{
Autosomal dominant onychodystrophy and congenital sensorineural deafness
}

\begin{abstract}
The disease "deafness and onychodystrophy" (DOD) is characterized by congenital hearing impairment and dystrophic or absent nails and teeth. The autosomal dominant form of the disorder has been previously reported only in one family. We describe here another family in which three members in three generations (a girl, her mother, and her maternal grandfather) were affected with DOD. Our finding is consistent with an autosomal dominant mode of inheritance and confirms autosomal dominant DOD (DDOD, MIM *124480) as a recognizable clinical entity.
\end{abstract}

Key words Deafness · Onychodystrophy · Autosomal dominant inheritance

\section{Introduction}

The disease "deafness and onychodystrophy" (DOD) is usually classified into two genetically distinct groups, an autosomal recessive form - DOOR (deafness, onychoosteodystrophy, mental retardation) syndrome (MIM *220500a) (Cantwell 1975; Sanchez et al. 1981; Lin et al. 1993 ) and a dominant (D) form (DDOD, MIM *124480) (Robinson et al. 1962). Clinically, patients with DOOR syndrome show features such as severe-to-mild mental retardation, seizures, mutism, hypotonia, congenital sensorineural deafness, triphalangeal thumb, and hypoplastic nails. The phenotypes of DDOD are milder than those of the recessive form (Robinson et al. 1962), and do not usually involve mental retardation. Only one family, involving five cases, has previously been associated with the dominant form of deafness and onychodystrophy (Robinson et al. 1962). Here we describe a second family with DDOD.

T. Kondoh $(\bowtie) \cdot$ A. Tsuru $\cdot$ T. Matsumoto $\cdot$ T. Matsuzaka $\cdot$ Y. Tsuji Department of Pediatrics, Nagasaki University School of Medicine, 1-7-1, Sakamoto-machi, Nagasaki 852-8501, Japan

Tel. +81-95-849-7298; Fax +81-95-849-7301

\section{Clinical report}

The pedigree of the family is shown in Fig. 1. The propositus is IV-7. Her maternal grandmother (II-11) had acquired hearing loss following an accident. Her father (III-3) was affected with bilateral congenital sensorineural deafness, but did not have any nail or tooth anomalies. There was no family history of deafness or onychodystrophy in his family. Consanguinity between her father (III-3) and her mother (III-5) was denied. The patients with deafness, onychodystrophy, and odontodysplasia are II-7, III-5, and IV-7. All these individuals had normal intelligence that enabled them to communicate fluently with other people using manual sign language.

\section{Proband - Patient IV-7}

The proband, a female, was the second infant born to a 32year-old gestation $(\mathrm{G}) 2$ partun $(\mathrm{P}) 2$ mother and a 43 -yearold father. The course of the pregnancy was uneventful. She was born vaginally, after 41 weeks' and 4 days' gestation, with no asphyxia. Her birth weight was $3064 \mathrm{~g}$. At age 8 months, she was referred to us because of suspected hearing loss. Her length was $67.5 \mathrm{~cm}(-0.3 \mathrm{SD})$ and weight, $7200 \mathrm{~g}$ $(-1.0 \mathrm{SD})$. Her facial appearance was not characteristic of DDOD, except for a flat nasal tip, high arched palate, and prominent ears. Her nails on the right II-IV and left I-V fingers were hypoplastic and the nails on the right thumb and fifth finger and all toes were absent (Fig. 2B). Her thumbs and fifth fingers were short, and there were single flexion creases in the fifth fingers of both hands. Her hair was not sparse. At age 1 year, teeth began to erupt. Deep tendon reflexes showed normal responses, and there were no abnormal reflexes. Her visual orientation response was good. However, auditory orientation response was poor. Parachute reactions were negative in forward and sideways positions. There was no response in the auditory brainstem evoked response examination against $105 \mathrm{~dB}$ sound bilaterally. Chromosomal analysis of peripheral blood lymphocytes showed a 46,XX karyotype. 
Fig. 1 Pedigree of an onychodystrophy-sensorineural deafness syndrome family. I-2 is suspected to have had the syndrome. Arrow shows the propositus

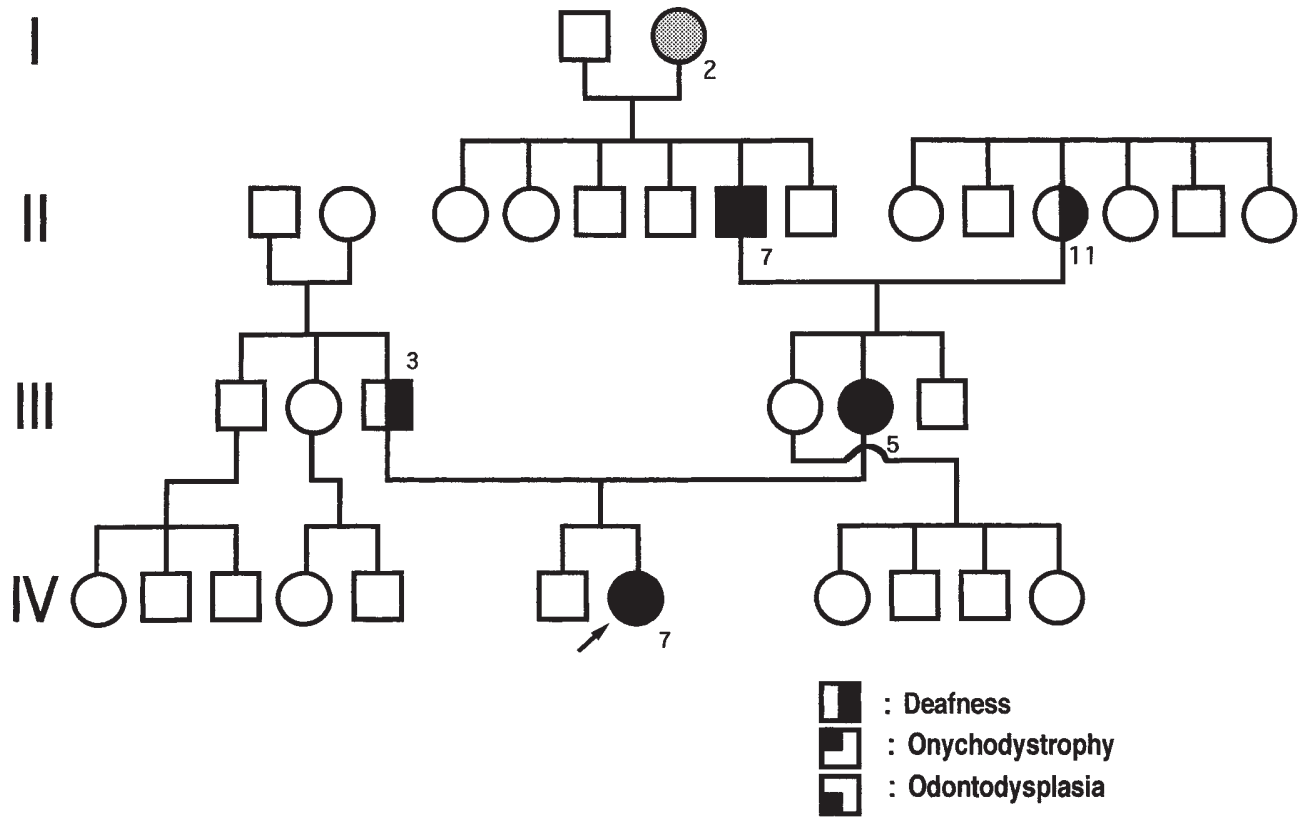

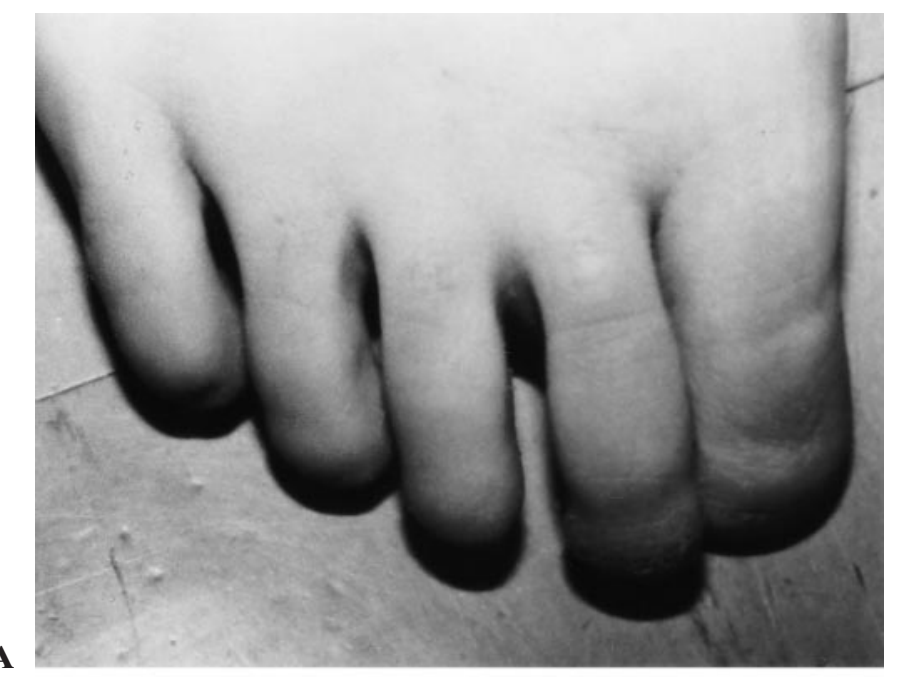

$\mathbf{A}$

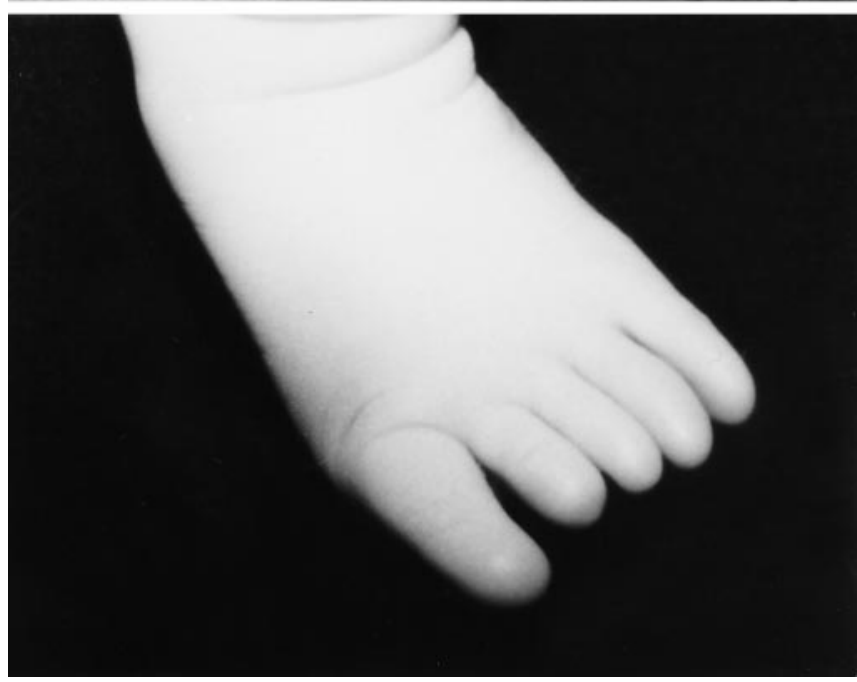

Fig. 2AB Photographs showing absent toenails in $\mathbf{A}$ mother of the propositus and $\mathbf{B}$ the propositus
Patient III-5

The mother of the proband was born vaginally, after 40 weeks' gestation, with no asphyxia. The course of the pregnancy was uneventful. Sensorineural deafness was noted at age 1 year. She could not walk until 2 age years, but the cause of this was unknown. She studied at special elementary, junior high, and senior high schools for people with impaired hearing. Her results at school were satisfactory. After studying dressmaking for 2 years at a vocational training school, she worked as a dressmaker.

She had no toe nails on either foot (Fig. 2A). Her fingernails were hypoplastic. Her scalp hair was not sparse. She had coniform or small permanent teeth. She had 32 teeth; the 4 back teeth had not grown.

The propositus's maternal grandfather (II-7) was also affected with congenital sensorineural deafness and had conical teeth with oligodontia, and dystrophic fingernails and toenails. His mother (I-2) was said to have been affected with the same disorder, although the details are unknown.

\section{Discussion}

The genetic details of this family were difficult to clarify, as three members (III-3 III-5, and IV-7) had congenital deafness and one (II-11) had acquired deafness. Since the maternal grandmother (II-11) had an acquired hearing impairment, this condition was not related to the genetic disorder. The father, III-3, had congenital deafness. As he is a sporadic case in his family, it is not known whether his hearing impairment was caused by an inherited disease. The mother and maternal grandfather had normal intelligence. A vertical and direct (male-female-female) transmission of 
the disease through three generations (or though four generations if the mother of the grandfather was also affected), is consistent with an autosomal dominant mode of inheritance, although an X-linked inheritance can not be completely ruled out.

The condition agrees well with the disorder in a family reported by Robinson et al. (1962), in which four members (the propositus, her two siblings, and their mother) had sensorineural deafness and dystrophic nails and teeth, and seems to be the second reported case of familial DDOD.

Embryologically, nails, teeth, and inner ear are all ectoderm-derived organs. Therefore, it is reasonable to assume that a causative gene for the disease may play a role in the developing ectoderm and its mutation may cause DDOD. Alternatively, a gene that regulates ectodermal differentiation may be deficient in DDOD patients. A number of ectodermal dysplasias and related disorders have been identified, and genes for some of these disorders have been isolated (Kere et al. 1996; McGrath et al. 1997). XLinked anhidrotic ectodermal dysplasia is characterized by abnormal hair, teeth, and sweat glands, and is caused by mutation in a transmembrane protein (Kere et al. 1996). Ectodermal dysplasis/skin fragility syndrome has features of both cutaneous fragility and congenital ectodermal dysplasia affecting skin, hair, and nails. Mutations in the plakophilin 1 gene result in this syndrome (McGrath et al. 1997). However, neither of these disorders fits the clinical manifestations of DDOD. Thus, the present kindred, together with the previous family (Robinson et al. 1962), represent a source that should be useful for mapping of the putative DDOD gene. Once the gene is mapped, it can be clarified whether DDOD and DOOR are allelic.

\section{References}

Cantwell RJ (1975) Congenital sensori-neural deafness associated with onycho-osteodystrophy and mental retardation (DOOR syndrome). Humangenetik 26: 261-265

Kere J, Srivastava AK, Montonen O, Zonana J, Thomas N, Ferguson B, Munoz F, Morgan D, Clarke A, Baybayan P, Chen EY, Ezer S, Saarialho-Kere U, dela Chapelle A, Schlessinger D (1996) X-Linked anhidrotic (hypohidrotic) ectodermal dysplasia is caused by mutation in a novel transmembrane protein. Nat Genet 13: 409-416

Lin HJ, Kakkis ED, Eteson DJ, Lachman RS (1993) DOOR syndrome (deafness, onycho-osteodystrophy, and mental retardation): A new patient and delineation of neurologic variability among recessive cases. Am J Med Genet 47: 534-539

McGrath JA, McMillan JR, Shemanko CS, Runswick SK, Leigh IM, Lane EB, Garrod DR, Eady RA (1997) Mutations in the plakophilin 1 gene result in ectodermal dysplasia/skin fragility syndrome. Nat Genet 17: 240-244

Robinson GC, Miller JR, Bensimon JR (1962) Familial ectodermal dysplasia with sensori-neural deafness and other anomalies. Pediatrics 30: 797-802

Sanchez O, Mazas JJM, de Dematos IO (1981) The deafness, onychoosteodystrophy, mental retardation syndrome. Hum Genet 58: 228 230 